EESTI NSV TEADUSTE AKADEEMIA TOIMETISED. XII KÖIDE FOOSIKA-, MATEMAATIKA. JA TEHNIKATEADUSTE SEERIA. 1963, NR. 1

ИЗВЕСТИЯ АКАДЕМИИ НАУК ЭСТОНСКОИ ССР. ТОМ ХІІ СЕРИЯ ФИЗИКО-МАТЕМАТИЧЕСКИХ И ТЕХНИЧЕСКИХ НАУК. 1963, № 1

\title{
ИЗМЕРЕНИЕ ИНТЕНСИВНОСТИ ИЗЛУЧЕНИЯ ФАКЕЛА РАДИОМЕТРАМИ НЕСТАЦИОНАРНОГО ТЕПЛОВОГО РЕЖИМА
}

\author{
и. эпик, А. ОтС, \\ кандидаты технических наук
}

\begin{abstract}
Часто при экспериментальных исследованиях теплопередачи и распределения интенсивности излучения факела в топках приходится измерять падающие лучистые потоки. Для этой цели удобно использовать раднометры нестационарного теплового режима, описание которых приведено А. К. Внуковым [']. Как показывает опыт авторов, применение радиометров является очень надежным и простым способом для измерения лучистых потоков в камерных топках при сжиганни эстонских сланцев.

При практических измерениях были использованы радиометры двух типов с толщиной измерительной диафрагмы 12,53 и 17,35 м..

В настоящей статье приводятся уточненные расчетные формулы для определения падающих лучистых потоков, а также результаты проверки радиометров сконструи-. рованным для этой цели водяным калориметром.
\end{abstract}

Если рассматривать диафрагму радиометра как бесконечную плоскую поверхность с конечной толщиной, что обеспечивается тепловой изоляцией боковых стен диафрагмы, пренебрегая собственное излучение передней стенки диафрагмы и считая падающий тепловой поток на диафрагму по времени постоянным (II граничное условие), то температуру пронзвольной точки диафрагмы в зависимости от времени можно рассчитать, как известно [ㄹ, из формулы

$t(x, \tau)=t_{0}+\frac{[q]}{\lambda}\left[\frac{a \tau}{\delta}-\frac{\partial^{2}-3 x^{2}}{6 \delta}+\delta \sum_{n=1}^{\infty}(-1)^{n+1} \frac{2}{\mu_{n}^{2}} \cos \mu_{n} \frac{x}{\delta} \exp \left(-\mu_{n}^{2} \mathrm{Fo}\right)\right]$

т'де

$x$ - координата диафрагмы, отсчитанная от задней стенки диафрагмы;

$\tau$ - время;

$\delta$ - толщина диафрагмы;

$t_{0}$ - начальная температура днафрагмы;

$[q]$ - тепловой поток; воспринимаемый диафрагмой;

$\lambda$ - коэффициент теплопроводности материала диафрагмы;

$a$ - коэффициент температуропроводности материала диафрагмы;

$F_{0}=\frac{a \tau}{\delta^{2}}-$ критерий Фурье;

$\mu_{n}=n \pi$. 
С другой стороны, воспринимаемое тепло диафрагмы

$$
[q]=c \gamma \delta \frac{d \bar{t}}{d \tau}
$$

где $c$ - удельная теплоемкость материала диафрагмы;

$\underline{v}$ - удельный вес материала диафрагмы;

$\bar{t}$ - средняя температура по толщине диафрагмы.

Средняя температура $\bar{t}$ определяется формулой

$$
\bar{t}=\frac{1}{\delta} \int_{0}^{\delta} t(x, \tau) d x=f(\tau) .
$$

Начиная от определенного значения Fó, член

$$
\delta \sum_{n=1}^{\infty}(-1)^{n+1} \frac{2}{\mu_{n}^{2}} \cos \mu_{n} \frac{x}{\delta} \exp \left(-\mu_{n}^{2} \mathrm{Fo}\right)
$$

в формуле (1) становится ничтожно малым в сравненин с остальными членами, и зависимость температуры каждой точки диафрагмы от времени является линейной, а от координаты - параболической, что выражается следую!цим образом:

$$
t(x, \tau)=t_{0}+\frac{[q]}{\lambda} \delta\left[\mathrm{Fo}+\frac{1}{2}\left(\frac{x}{\delta}\right)^{2}-\frac{1}{6}\right] .
$$

Согласно этому, можно вывести следующие зависимости для расчета, температуры передней и задней стенок диафрагмы:

$$
\begin{aligned}
& t_{1}(\tau)=t_{0}+\frac{[q]}{\lambda} \delta\left(F o-\frac{1}{3}\right) \\
& t_{2}(\tau)=t_{0}+\frac{[q]}{\lambda} \delta\left(F o-\frac{1}{6}\right) .
\end{aligned}
$$

Практическн формулы (4), (5) и (6) можно кепользовать начиная

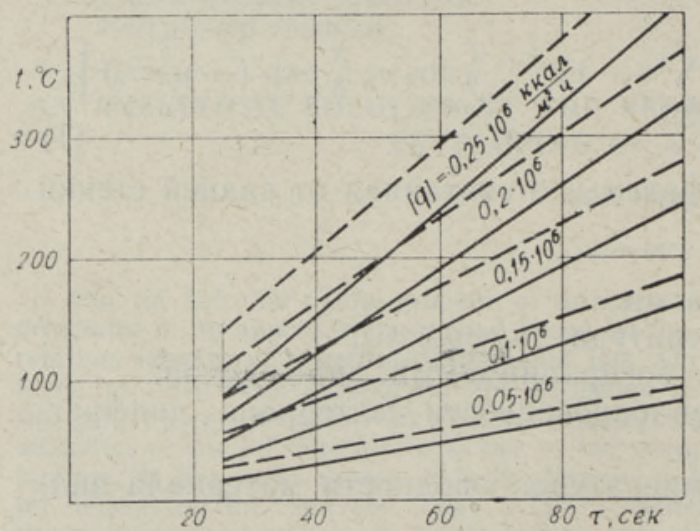

Pис. 1. Зависимость температуры передней и задней стенок диафрагмы радиометра $\delta=$ $=17,35$ м. от временн н тепловой нагрузки. от $\mathrm{Fo}=1$. Ошибка прн этом не превышает $0,01 \%$.

На рис. 1 показана зависнмость температуры передней и задней стенок от времени при различных значениях $[q]$ для диафрагмы $\delta=17,35$ мм, изготовленной из углеродистой стали (при $250^{\circ} \mathrm{C}-\gamma=7,787$ $2 / \mu^{3}, \quad \lambda=41,0 \kappa \kappa a \Omega / \mu \cdot u \cdot{ }^{\circ} \mathrm{C}$ и $c=0,120 \kappa \kappa a л / \kappa 2 \cdot{ }^{\circ} \mathrm{C}$ ), начиная от критерня Фурье Fo $=1$. Для данной диафрагмы соответствует приблизительно «время ожидания» 25 сек. Прямые построены для начальной температуры диафрагмы $t_{0}=0^{\circ} \mathrm{C}$. Сплошными линиями нанесена 
температvра задней стенки, а пунктирными - температура передней стенки диафрагмы.

Начиная от Fo > Fó можно формулу для расчета теплового потока, прннимаемого диафрагмой радиометра рассчитать по конечным разностям температуры и времени

$$
[q]=c \gamma \delta \frac{\Delta t}{\Delta \tau} .
$$

Формулу (7) для расчета теплового потока рекомендует использовать A. K. Внуков [1], но без ограничивающего условия Fo $>$ Fó. Tаким образом, формула (7) является достаточно точной тогда, когда зависимость температуры диафрагмы от времени является линейной, что в действительности достигается после некоторого промежутка времени («время ожидания»), определяемого непосредственно величиной Fö. Из этого также следует, что замерить подъем температуры можно из любой точки диафрагмы, поскольку температура диафрагмы зависит от времени по линейному закону.

При расчете теплового потока по формуле (7) получаем тепловой поток при данной температуре передней стенки диафрагмы $t_{1}$. Для определения интенсивности излучения факела нужно учитывать собственное излучение диафрагмы радиометра и отраженное от нее излучение. Учитывая собственное излучение диафрагмы коэффициентом собственного излучения $\beta=\frac{q_{\text {coб }}}{[q]}$, где $q_{\text {соб }}$ - тепло, излучаемое диафрагмой, то тепловой поток, который радиометр принял бы при температуре передней стенки $0^{\circ} \mathrm{K}$, будет

$$
q^{\prime}=(1+\beta)[q]
$$

Если термопара-для измерения подъема температуры зачеканена $k$ задней стенке диафрагмы, то по ее показаниям нетрудно расчитать коэффициент собственного излучения диафрагмы из формулы

$$
\beta=\varepsilon_{\mu} \sigma_{0} \frac{T_{1}^{4}}{[q]}=\varepsilon_{\mu} \sigma_{0} \frac{\left(T_{2}+\frac{1}{2} \frac{\delta}{\lambda}[q]\right)^{4}}{[q]} .
$$

На рис. 2 показана зависимость коэффициента $\beta$ от теплового потока $[q]$ для диафрагмы толщиной $\delta=17,35$ мм при температуре задней стенки диафрагмы 188 и $235^{\circ} \mathrm{C}$. Степень черноты диафрагмы $\varepsilon_{д}=$ $=0,82$. При данной температуре передней стенки диафрагмы коэффициент собственного излучения диафрагмы уменьшается с увеличением тепловой нагрузки.

Падаюший поток излучения

$$
q_{\text {naд }}=\frac{q^{\prime}}{\varepsilon_{\mathrm{a}}} .
$$

Для проверки полученных данных при использовании радиометров нестационарного теплового режима был сконструирован водяной калориметр, схема которого приведена на рис. 3. Калориметр имел рабочий участок диаметром 100 мм, который внутри был снабжен спиралью для направления движения воды. Для тепловой изсляции боковых стен калориметра рабочий участок был окружен кольцевым водяным каналом. Направление движения воды в кольцевом канале совпадало с на- 


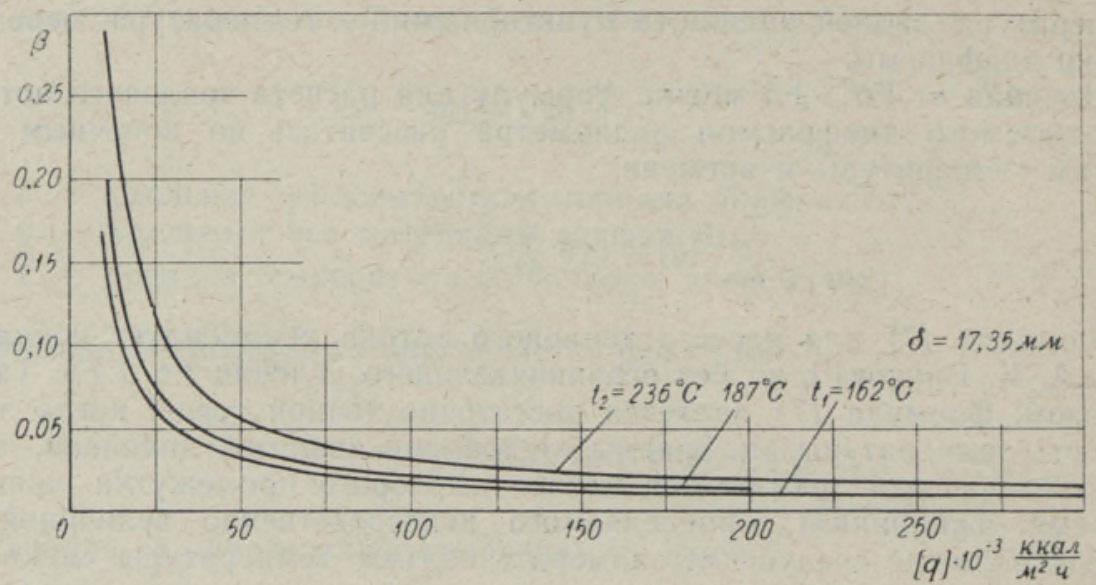

Рис. 2. Зависимость коэффициента собственного излучения от тепловой нагрузки и температуры задней стенки диафрагмы $\delta=17,35$ мм.

правлением движения воды в спирали. Расход воды через кольцевой канал регулировался так, чтобы температура воды на выходе из коль-

Pवзрез ББ

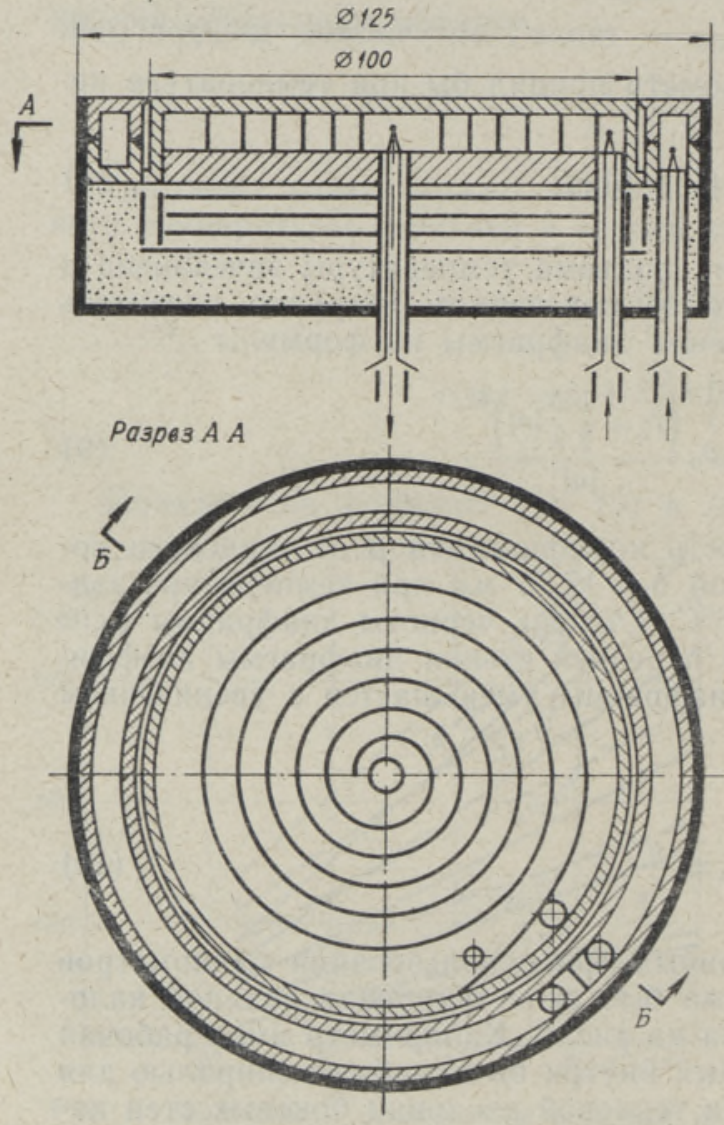

Рис. 3. Схема водяного калориметра. цевого канала равнялась температуре воды после первой. закрутки спирали. Для тепловой изоляции задней A стенки использовались мно гократные защитные экраны.

Проверка показаний радиометров с показаниями калориметра была проведена в электропечи, которая давала возможность менять температуру излучающего тела в широком диапазоне.

Результаты проверки приведены на рис. 4, где на вертикальной оси нанесены показания стационарного водяного калориметра, а на горизонтальной оси - показания радиометров нестационарного теплового режима. Тепловые потоки, измеренные радиометрами, совпадают с показаниями калориметра с точностью $\pm 10 \%$, что можно считать достаточным для большинства технических измерений. Совпадение результатов проверки при применении радиометра c диафрагмой толщиной 12,53 мм хуже, чем при проверке радиометром 17,35 м.. Это, по всей вероятности, 


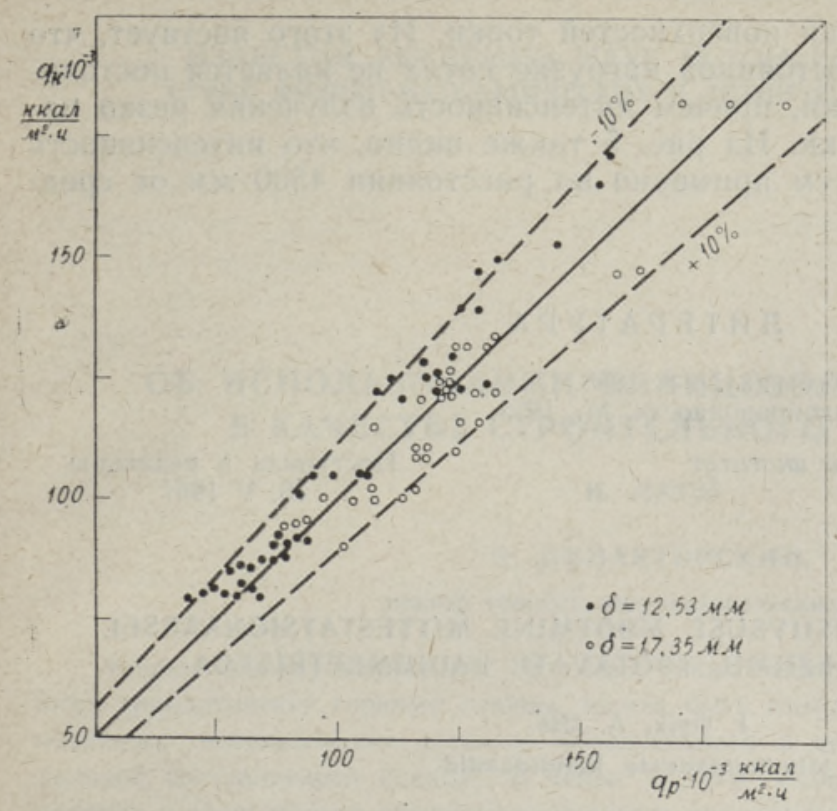

Рис. 4. Результаты проверки. объясняется более высокими тепловыми потерями боковых стен диафрагмы толщиной 12,53 мм, т. к. толщина компенсирующих колец в обоих случаях была 17,35 мм. Поэтому показания радіюметра с диафрагмой толщиной 12,53 мм несколько меньше показаний калориметра, особенно гіри высоких тепловых нагрузках. Из этого можно сделать вывод, что толщина диафрагмы и ком. пенсирующих колец должна быть одина ковой.

Для иллюстрацин на рис. 5 приведены практические результаты измерений интенсивности излучения факела в топке котла высокого давления ТП-17 производительностьо 220 т/4 при сжигании пыли эстон-

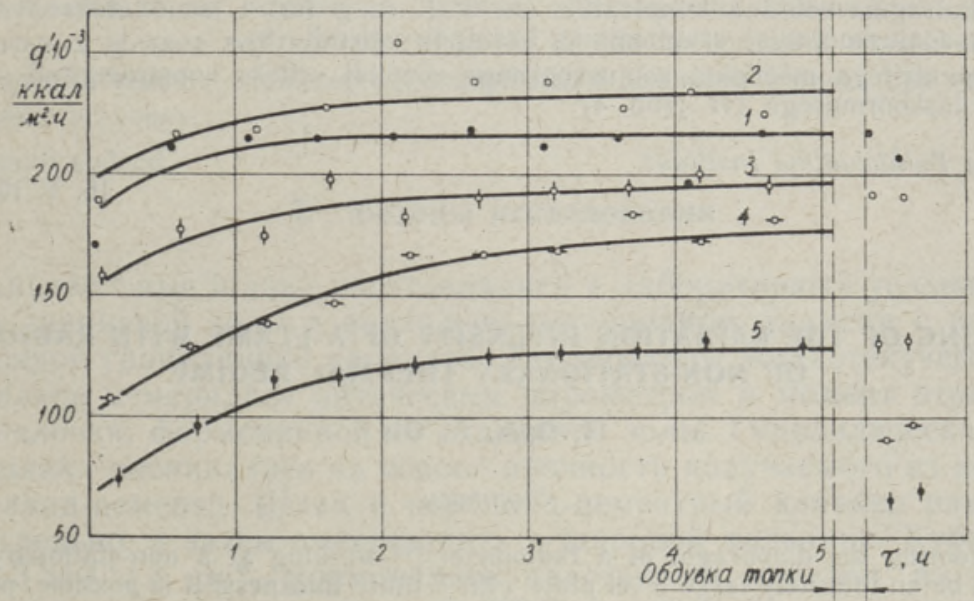

Рис. 5. Зависимость интенсивности излучения пылесланцевого факела от времени на различных высотах $x$ от среднего уровня горелок.

$$
1-1,7 \mu ; 2-4,7 \mu ; 3-8,3 \mu ; 4-9,2 \mu ; 5-12,8 \mu .
$$

ских сланцев. Котел оборудован угловыми многощелевыми горелками. Опыт проведен при средней нагрузке котла $176 \mathrm{~T} / 4$. На вертикальной оси поставлены результаты измерений, обработанные по формуле (8), а на горизонтальной оси - время. Каждая кривая соответствует определенному ярусу по высоте топки. Из приведенного графика виден характер изменения интенсивности пылесланцевого факела от времени, а также и от высоты топки. Время $\tau=0$ соответствует моменту непо- 
средственно после обдувки поверхностей топки. Из этого явствует, что нзлучение факела при постоянной нагрузке котла не является постоянным и зависит от времени, причем интенсивность излучения резко падает в резульгате обдувки. Из рис. 5-также видно, что интенсивность нз.лучения имеет максимум примерно на расстоянии 4500 мм от среднего уровня горелок.

\title{
ЛИТЕРА Т У РА
}

1. А. К. В н уков, Теплоэнергетнка № $8,1958$.

2. А. В. Л ы ков, Теория теплопроводности, М., 1952.

Таллинский политехнический институт

Поступила в редакцию

16. V 1961

\section{LEEGI KIIRGUSINTENSIIVSUSE MOOOTMINE MITTESTATSIONAARSEL SOOJUSLIKUL REŻIMIL TÖOTAVATE RADIOMEETRITEGA}

\author{
I. Öpik, A. Ots, \\ tehnikateaduste kandidaadid
}

\section{Resümee}

Käsitades kōnesoleva radiomeetri ['] diâfragmat kui lōpliku paksusega lōpmata suurt tasapinnalist plaati, vōib Fourier' kriteeriumist $\mathrm{Fo}=1$ alates temperatuuri sōltuvust ajast vaadelda diafragma meelevaldses punktis lineaarsena. Diafragma tagaseina temperatuuri järgi on arvutatav tema esiseina omakiirgus. mida soojuskoormuste arvutamisel soovitatakse arvesse vōtta omakiirgusteguri $\beta$ năol (vt. valem (9) ja joon. 2).

Kui diafragma esiseina temperatuur on $0^{\circ} \mathrm{K}$ ning Fo $>1$, soovitatakse radiomeetri diafragma soojuskoormuse arvutamiseks kasutada valemit (8).

Radiomeetritega mõōdetud soojuskoormusi vōrreldi selleks konstrueeritud vesikalorimeetri soojuskoormusega (vt. joon. 4).

Tallinna Polütehniline Instituut

Saabus toimetusse

16. V 1961

\section{MEASURING OF THE RADIATION INTENSITY OF A FLAME WITH RADIOMETERS OF NON-STATIONARY THERMAL REGIME}

\author{
1. Opik, A. Ots
}

\section{Summary}

Considering the diaphragm of a radiometer [1] working at a non-stationary thermal regime to be an infinitely large level plate with a finite thickness, it is possible, proceeding from Fourier's criterium Fo $=1$, to regard the dependence of the temperature on time, at any point of the diaphragm, to be linear. Measuring the temperature of the back wall of the diaphragm we can compute the emission of the front wall of the diaphragm, which it is advisable to take into consideration, as the factor of self-radiation $\beta$ (see formula (9) and fig. 2), when computing heat loads.

When computing the heat load of the diaphragm of the radiometer and taking the temperature of the front wall of the diaphragm $0^{\circ} \mathrm{K}$ and $\mathrm{Fo}>1$, it is convenient to use formula (8).

The heat loads measured with radiometers were compared with the heat loads of specially constructed water calorimeters. The results of the comparison are shown in fig. 4 . 